\title{
A recepção crítica do romance O Coruja, de Aluísio Azevedo
}

\author{
The critical reception of the novel O Coruja, by Aluísio Azevedo
}

\author{
MARIA VIANA \\ Universidade Nova de Lisboa. Lisboa, Portugal.
}

\begin{abstract}
Resumo: De maneira geral, costuma-se agrupar a obra de Aluísio Azevedo em dois segmentos. De um lado, ficariam obras de indiscutível qualidade literária, caso de $O$ cortiço, Casa de pensão e $O$ Mulato; de outro, os livros destinados às folhas matutinas e, portanto, escritos para atender à demanda dos leitores de jornais. Essa divisão contribuiu para que grande parte dos romances desse escritor, despertasse pouco interesse de estudo por parte da crítica. No caso da obra $O$ Coruja, alguns críticos a condenam; outros consideram suas qualidades, mas lamentam o fato de o romance ter sido escrito apressadamente para ser publicado como folhetim. Por isso, achamos relevante apresentar neste artigo breve explanação sobre a recepção da obra de Aluísio Azevedo, com destaque para o romance $O$ Coruja.
\end{abstract}

Palavras-chave: Aluísio Azevedo; O Coruja; Fortuna crítica.

\begin{abstract}
Absctrat: In general, it is customary to organize the novels of Aluísio Azevedo into two segments. On the one hand, they would be books of indisputable literary quality $(O$ cortiço, $O$ homem and $O$ mulato); on the other, the books written for the morning paper and, therefore, written to meet the demands of newspaper readers. That division contributed to some novels by Aluísio Azevedo are little studied. In the case of book O Coruja, some critics condemn; others critics consider their qualities, but they talk the fact that novel be written hastily, for be published in serial. Therefore, we present in this article relevant brief explanation about the reception of the work of Aluísio Azevedo, especially the novel O Coruja.
\end{abstract}

Keywords: Aluísio Azevedo; O Coruja; Critical fortune.

Entre os primeiros que saudaram a estreia de Aluísio Azevedo como romancista está Araripe Júnior. ${ }^{1}$ Durante o ano de 1888, esse crítico publicou uma sequência de 25 artigos na revista Novidades, ${ }^{2}$ em que analisa a influência de Zola na produção do escritor maranhense.

A série de textos tem início com uma espécie de panorama histórico, em que trata da evolução do romance desde a epopeia clássica até a produção do século XIX.

\footnotetext{
No final da década de 1950, os textos desse importante crítico brasileiro, que estavam dispersos em várias fontes, foram reunidos e editados em cinco volumes, como resultado da pesquisa de estudiosos da Casa Rui Barbosa, sob a direção de Afrânio Coutinho. Os artigos que nos interessam estão em Obra crítica de Araripe Júnior, v. II (1888-1894). Rio de Janeiro: Ministério da Educação e Cultura e Casa Rui Barbosa, 1960. Muito embora, já em 1881, o crítico tivesse escrito sobre $O$ Mulato e, em 1884, saudado o lançamento Casa de pensão.

2 Ver JÚNIOR, Araripe. "A Terra, de Emílio Zola, e o Homem, de Aluísio Azevedo". In: Obra crítica de Araripe Júnior, v. II. Rio de Janeiro: Casa de Rui Barbosa, 1958, p. 25 a 94.
}

Isso porque, para Araripe Júnior, “[...] o romance, ou o episódio pitoresco da vida, tem por base a ficção, tendência existente no homem desde a época em que suas faculdades atingiram certo desenvolvimento psíquico." (JÚNIOR, 1958, p.28.) Portanto, para esse estudioso, a fórmula encontrada pelos romancistas do século XIX não apareceu arbitrariamente, foi se condensando ao seguir um percurso de tradição nos diferentes países, atingido sua forma exemplar na Inglaterra, com escritores como Jonathan Swift, Daniel Defoe e, principalmente, Walter Scott.

Vários artigos dessa obra são dedicados à tradição francesa até chegar em Émile Zola. Para Araripe Júnior, o grande mérito desse escritor estaria na maneira como conseguiu proceder "à desintegração das formas do romance fisiológico, para depois integrá-lo sob o ponto de vista sociológico" (JÚNIOR, 1958, p. 45). O crítico elogia 
a grande capacidade do escritor maranhense de manter a unidade artística de uma obra, o que certamente exigia muita energia e engenhosidade arquitetônica.

No entanto, para Araripe Júnior, Aluísio Azevedo estaria mais perto de exercer no Brasil um papel correspondente ao de Balzac na França, do que o feito por Zola, apesar de acreditar que, para isso, o escritor tivesse de estudar muito até conquistar um estado de ilustração que lhe permitisse ir além do que havia conseguido até então. Vale dizer que Aluísio pouco produziu depois desses artigos de Araripe Júnior, que faz menção às obras do escritor desde o romance de estreia, $O$ Mulato, passando por Casa de pensão, O Coruja, O homem até chegar em $O$ cortiço.

Portanto, dado que Aluísio pouco escreveu depois que assumiu a carreira diplomática, em 1895, não pôde por certo seguir as recomendações de Araripe Júnior para tornar-se o "Balzac brasileiro", e tampouco sabemos se concordaria com tal sugestão. O estudioso também reitera que o autor d' $O$ cortiço jamais foi um mero copista dos moldes do Naturalismo francês, uma vez que criou uma fórmula nova, a única possível em um país jovem como o Brasil.

A opinião de Araripe Júnior sobre $O$ Coruja difere muito da que tem sobre Casa de pensão e $O$ cortiço. Segundo ele, enquanto nestes dois livros o espírito do romancista abrange e trata com facilidade a ligação das personagens entre si e com os aspectos exteriores, em $O$ Coruja seu problema foi justamente querer criar um romance de tese. Ou seja, para esse estudioso, quando Aluísio Azevedo tenta escrever uma obra diferente do que ele chama de "essencialmente representativo" e envereda para o caminho das memórias e das confissões, "pode conseguir resultados até certo ponto; mas não tardará em saltar fora do molde, perturbando assim a harmonia da obra de arte" (JÚNIOR, 1958, p. 88).

Não obstante a importância da crítica de Araripe à obra alusiana - que, como vimos, foi precedida de vasta e rigorosa explanação sobre o romance, o que bem demonstra sua grande erudição -, seu julgamento estava permeado por ideias pautadas em sua filiação naturalista. Chegou a acreditar, por exemplo, que os problemas dos romancistas brasileiros, inclusive seus deslizes gramaticais, advinham das adversidades climáticas: "O tropical não pode ser correto. A correção é o fruto da paciência e dos países frios; nos países quentes a atenção é intermitente" (JÚNIOR, 1958, p. 88).

O crítico José Veríssimo também aponta as influências francesas na obra de Aluísio Azevedo. Mas antes de tratar da obra desse escritor, faz um preâmbulo sobre o naturalismo francês. Segundo ele, o grande demérito desse movimento literário foi a vulgarização da arte:
Os seus assuntos prediletos, o seu objeto, os seus temas, os seus processos, a sua estética, tudo nele estava ao alcance de toda a gente, que se deliciava com se dar ares de entender literatura discutindo de livros que traziam todas as vulgaridades da vida ordinária e se lhe compraziam na descrição minuciosa. Foi também o que fez efêmero o naturalismo, já moribundo em França quando aqui nascia (VERÍSSIMO, 1998, p. 340).

Ao discorrer sobre as obras dos três representantes do Naturalismo no Brasil - Aluísio Azevedo, Júlio Ribeiro e Raul Pompéia -, o crítico explicita a sua predileção pela obra $O$ Ateneu, para ele, a mais original produzida no período, justamente por não ter seu autor se pautado tanto no modelo francês, muito embora o livro não fosse tão bem composto como as melhores obras de Aluísio Azevedo: $O$ cortiço, O homem e Casa de pensão. No capítulo dedicado ao Naturalismo e ao Parnasianismo, no seu livro História da Literatura Brasileira, apenas esses três livros do escritor maranhense são mencionados, além de breve alusão à obra $O$ Mulato. Para Veríssimo, "O resto de sua obra, de pura inspiração industrial, é de valor somenos" (VERÍSSIMO, 1998, p. 341).

Portanto, dos dois críticos contemporâneos a Aluísio Azevedo aqui retomados, apenas Araripe Júnior debruçou-se um pouco mais sobre a obra do escritor maranhense e, ainda assim, pouco escreveu sobre $O$ Coruja. E o que teriam dito os críticos posteriores sobre esse romance?

Em discurso proferido na sessão solene extraordinária do dia 21 de julho de 1914 para ocupação da cadeira 4, que pertencera a Aluísio Azevedo, Alcides Maya disserta sobre o esforço desse escritor em implementar o Naturalismo no Brasil. Para ele, essa escola literária não teve êxito pois, ao querer "arrancar ao artista a sua faculdade característica, esqueceu que a arte é realidade idealizada, não a cópia da realidade; e falhou por isso, por haver tentado substituir o símbolo pelo modelo, a intuição pela experiência, a síntese pela análise". ${ }^{3}$

Alcides Maya apresenta um panorama da produção do escritor maranhense, em que aponta $O$ cortiço como "o mais perfeito de seus romances", para, logo em seguida, dedicar longo parágrafo à obra $O$ Coruja. Transcrevemos a seguir esse trecho na íntegra, pois, além de sua importância, o mesmo é retomado por críticos posteriores.

Entretanto, a grande criação de Aluísio Azevedo é outra, é uma figura sombria crispada comicamente a sofrimentos de tragédia interior, é um ser humilde, feio e miserável, quase Alceste, meio Quasímodo,

\footnotetext{
3 Ver MAYA, Alcides. Discurso proferido na sessão solene extraordinária do dia 21 de julho de 1914 na Academia Brasileira de Letras. Disponível em: <http://www.academia.org.br/abl/media/Tomo\%20I\%20-\%20 1897\%20a\%201919.pdf>. Acesso em: fevereiro de 2017.
} 
triste como a dor, grande como um protesto atirado ao destino, é o Coruja. Esta criatura de arte, que roça pelo símbolo, não tem rival no romance brasileiro. À verdade pessoal junta a poesia amarga de um combate sem tréguas com a sorte injusta. Ergue-se na existência como a imagem do dever e é o dever que o esmaga; a sua única ventura é a bondade e chega a duvidar dela, a odiá-la; o amor é o seu sonho de todas as horas e só inspira aversão; possui todas as virtudes e são as próprias virtudes que o atraiçoam, que o condenam à derrota, que o matam. Ah! que pena sentimos pensando no que poderia ter sido $O$ Coruja, se Aluísio Azevedo houvesse compreendido o valor excepcional, na sua obra, dessa criação! É o seu volume mais descuidado, talvez o único de que desdenhara. Dá-nos a impressão de ter sido composto às pressas, sobre o joelho. Registram-se casos assim na vida literária: quem soube penetrar em tantas consciências, não se entendeu a si mesmo... (MAYA, 1914, s./p.).

Se, por um lado, Alcides Maya defende as qualidades do romance, sobretudo a construção da personagem André; por outro, lamenta o fato de o escritor tê-lo redigido às pressas. De certa forma, há nesse posicionamento a sentença decretada posteriormente por grande parte da crítica, que passa a dividir a obra de Aluísio Azevedo em dois grupos: os livros preparados com calma para edição definitiva e os produzidos rapidamente para figurar como folhetins.

Essa divisão é também defendida pela pesquisadora, Lúcia Miguel-Pereira, para quem o Naturalismo entre nós foi ainda mais postiço do que o Romantismo. Sua posição é a de que só quando o Realismo teve matiz exagerado, dando origem ao Naturalismo, coroado com o êxito retumbante de Zola na França e de Eça de Queirós em Portugal, é que se instalou definitivamente no Brasil com a obra de Aluísio Azevedo.

Ao analisar a obra dos escritores naturalistas, a estudiosa destaca as limitações impostas pelas regras da nova escola: "o fatalismo que, privando total e exageradamente de arbítrios as personagens, lhes mecaniza os conflitos; a escravização ao concreto, cerceando o poder criador; o moralismo, o pedantismo, a prolixidade, a declamação" (MIGUEL-PEREIRA, 1957, p. 156).

Ao se deter na obra de Aluísio Azevedo especificamente, Miguel-Pereira afirma que ele não realizou inteiramente sua vocação como escritor, pois "Houve como que uma impotência nesse romancista profuso - a impotência dos criadores que não superam a realidade tangível, porque a observação neles não se prolonga pelo senso estético" (MIGUEL-PEREIRA, 1957, p. 137). Apesar de mais frequentemente apontar os problemas de construção da obra alusiana como um todo, a estudiosa afirma que a grande contribuição de Aluísio Azevedo foi a sua capacidade de fixar as coletividades, como observa nas obras Casa de pensão e $O$ cortiço.
Lúcia Miguel-Pereira faz apenas duas alusões à obra O Coruja. A primeira para dizer que, a despeito de ter sido escrita caprichosamente, como foi também o caso de $O$ homem, Filomena Borges e O livro de uma sogra, trata-se de uma obra ilegível. A segunda vez que se refere ao romance é para compará-lo à construção bem-sucedida de $O$ cortiço e outras criações do escritor. Em seguida, afirma que em Casa de pensão e $O$ Coruja o escritor determina de antemão o futuro das personagens e isso fragiliza a construção.

Em certa altura de sua análise, Miguel-Pereira afirma que, ao seguirem os passos de Zola e Eça de Queirós, os naturalistas brasileiros não atentaram para as diferenças entre as sociedades francesa e portuguesa e o nosso meio, que ainda estava em formação: “[...] sem perceberem que o que lá refletia a desagregação da burguesia, aqui não passava de anedota isolada" (MIGUEL-PEREIRA. 1957, p. 130).

Josué Montello, em capítulo que assina no livro A literatura no Brasil: Era realista, Era de transição, também faz interessante estudo sobre o Naturalismo brasileiro. Como os críticos anteriores, apresenta o período na perspectiva da influência estrangeira, pois acredita que: "[...] as transformações aqui não se realizam organicamente, de dentro para fora, como resultado da própria evolução da consciência nacional, mas como reflexo das ideias-forças de origem estrangeira". (MONTELLO, 1997, p. 75.) Todavia, diferentemente dos outros estudiosos até aqui apresentados, vê influência maior de Eça de Queirós sobre Aluísio Azevedo e outros escritores naturalistas em detrimento da influência francesa. Mas reitera que em nenhum dos representantes do Naturalismo brasileiro pode se encontrar "a ironia corrosiva com que Eça, na pintura da sociedade portuguesa, atendeu a seus propósitos de demolição" (MONTELLO, 1997, p. 74.).

No que diz respeito à obra de Aluísio Azevedo, como os críticos anteriores, Josué Montello também separa a obra alusiana entre bons romances e aqueles escritos para figurar em folhetins. Todavia, além de laurear Casa de pensão e $O$ cortiço, destaca também $O$ Homem, O livro de uma sogra e $O$ Coruja, que considera como "obras sérias, à altura de seu renome e de sua vocação" (MONTELLO, 1997, p. 78-9). Sobre o Coruja, escreve:

O Coruja parece ter sido elaborado sob o impulso da instantaneidade criadora que presidiu a redação dos romances de folhetim que Aluísio Azevedo disseminou na imprensa da Corte. Mas a verdade é que o livro, embora derivado dessa escrita de afogadilho, está longe de pertencer à categoria de trabalhos perecíveis em que se enquadram $A$ mortalha de Alzira e as Memórias de um condenado (MONTELLO, 1997, p. 79). 
Cabe destacar também que neste mesmo volume de A literatura no Brasil, Afrânio Coutinho faz interessante distinção entre o Realismo e o Naturalismo para concluir que, não fosse um ou outro livro de Aluísio Azevedo, Domingos Olímpio e Adolfo Caminha, poder-se-ia dizer que esse foi um movimento gorado no país, a despeito de suas influências poderem ser notadas em quase todos os escritores do período:

Pode-se mesmo afirmar que raros foram os escritores do final do século XIX e começo do XX que não se deixaram contaminar das ideias diretoras do Naturalismo. Mesmo a obra de Machado de Assis dele está impregnada, pois, cioso de sua independência e reagindo contra os seus exageros, não ficou imune à sua influência e soube (COUTINHO, 1997, p. 19).

Dada a grande importância da crítica positivista e materialista no Brasil para a chamada geração de 1870 , Afrânio Coutinho assina o capítulo intitulado "A crítica naturalista positivista". Nele o crítico tece interessante panorama sobre o ideário crítico que norteou as escolas de Recife e Fortaleza, seguido da súmula do pensamento de críticos como Sílvio Romero, Capistrano de Abreu, Araripe Júnior e José Veríssimo.

Apesar do elogioso comentário, Afrânio Coutinho não apresenta nenhuma análise da obra e apenas menciona Alcides Maya como o único grande crítico a chamar atenção para a qualidade do romance, transcrevendo exatamente parte do trecho citado por nós, quando mencionamos o discurso de pose do sucessor de Aluísio Azevedo na Academia Brasileira de Letras.

Eugênio Gomes é dos poucos que, a nosso ver, apresenta uma abordagem diferente da linha geral seguida pelos críticos antecessores. Isso porque, além de não se estender em análises demoradas sobre a influência europeia na produção alusiana, aponta as falhas da crítica ao organizar as obras do autor em dois segmentos: "É simples admitir que a pressa de fazer livros sobre livros o tivesse desencaminhado, obrigando-o a alinhavar as suas narrativas com o olho fixo no mercado. Mas o exame de suas ideias estéticas e de seus processos mostrará que as deficiências de sua obra têm outra explicação" (GOMES, 1958, p. 113).

Essa explicação estaria no que o crítico chamou de "hibridismo de uma estética de transição". Eugênio Gomes desenvolve sua teoria a partir de depoimentos dados pelo próprio Aluísio sobre a dificuldade de se escrever obras naturalistas no país. Segundo ele, diante do dilema de escrever para os leitores que estavam em pleno romantismo e para o pequeno grupo de críticos que acompanhavam a evolução do romance moderno, a opção do escritor foi conciliar as duas demandas. Portanto, quando alguns críticos estranharam a dosagem de Romantismo que Aluísio Azevedo aplicara em suas criações ditas naturalistas "[...] não fizeram mais do que escancarar a porta que o romancista deixara voluntariamente aberta. Isso significa que foi o próprio escritor maranhense que denunciou o hibridismo de sua estética de transição (GOMES, 1958, p. 113).

Esse crítico baiano foi também um dos poucos a escrever alguns parágrafos sobre a obra $O$ Coruja. O estudioso retoma a visão de Alcides Maya, apesar de considerá-la por demais elogiosa, pois acredita que o grande problema do romance está justamente no fato de Aluísio ter construído uma personagem excessivamente boa, no caso André, e, sobretudo, por ter postulado isso logo no início do romance. ${ }^{4}$

De fato, no final da primeira parte da obra, quando André vê d. Laura, mãe de Teobaldo, despedir-se do filho, com uma manifestação de afeto que ele jamais recebera, decide ser "bom". Mas por que teria Aluísio, já na primeira parte do romance, apresentado de forma tão explícita essa característica da personagem que dá título à obra, escancarando assim o que poderia ter urdido de maneira sutil durante a construção do romance? Teria construído as duas personagens centrais do romance para justamente demonstrar tanto a impossibilidade da bondade absoluta de André, que, torna-se um homem amargo e infeliz, como a excessiva vaidade de Teobaldo, que o conduziu a um final trágico?

O romantismo apontado por Eugênio Gomes é também um dos pontos tratados por Sérgio Milliet na introdução ao romance $O$ cortiço, para a coleção "Obras completas de Aluísio Azevedo". Mas, diferente do crítico baiano, que viu os traços românticos como uma opção deliberada do escritor maranhense, Milliet acredita que em Aluísio esse temperamento romântico fundamental "que o impele a escrever $O$ Coruja, ao gosto hugoano da antítese do bem e do mal" (MILLIET, 1959, p. 14) - é que fez com que esse romance, apesar do valor literário, não bastasse para que seu autor pudesse ser considerado o maior representante do naturalismo brasileiro, título conquistado indubitavelmente com $O$ cortiço.

No prefácio para o romance $O$ Coruja escrito para figurar entre as obras completas publicadas pela Livraria Martins Fontes, Raimundo de Menezes pouco acrescenta ao visto até aqui. Ele retoma a crítica de Alcides Maya e as contrapõe, usando as hipóteses empregadas por Eugênio Gomes. As informações novas não são de cunho estético, mas vamos mencioná-las à guisa de curiosidade.

\footnotetext{
4 "Pela simples técnica de apresentação inicial no romance, Coruja estava fadada a ser um paralítico, no plano da criação artística, não pelo defeito físico, que the valeu o apelido grotesco, mas porque o romancista o inutiliza desde o primeiro toque, quando se decide a projetá-la como figura autônoma. [...] Aluísio Azevedo prejulga de maneira incisiva o personagem, em vez de levar o leitor insensivelmente a assistir o fracasso de idealismo absurdo através do desenvolvimento da ação." GOMES, Eugênio. Aspectos do romance brasileiro. Bahia: Progresso, 1958, p. 126.
} 
O estudioso reproduz citação de Almeida Prado, na qual este afirma que Aluísio Azevedo passou pela vida um pouco como seu personagem Teobaldo. Hipótese com a qual discordamos. A grande capacidade de trabalho do romancista está bem longe do diletantismo da personagem em questão. Cita também Augusto Fragoso, que viu em André uma caricatura de Capistrano de Abreu, tipo excêntrico pouco afeito a glórias e obsedado pela ideia de escrever um livro sobre a história do Brasil. Comparação também indevida, pois diferente de André, que não termina sua obra, o mesmo não podemos dizer das contribuições valiosas de Capistrano de Abreu como historiador.

Nesse sentido, o prefácio de Nogueira da Silva, da edição de $1954,{ }^{5}$ é bem mais contundente. O estudioso vê ponto de contato entre os romances $O$ Coruja e Casa de pensão. Além de levantar a hipótese de que a divisão do romance em três grandes partes, que podem ser lidas separadamente, desperta "a impressão vigorosa e funda de serem, de per si, romances à parte" (SILVA, 1954, p.12). Nogueira da Silva destaca ainda a maestria com que Aluísio conduz os diálogos durante a narrativa, de maneira natural, espontânea e lógica, afastando-os da retórica empolada. Aponta também a maneira impecável como o escritor traçou o perfil de André e as personagens que gravitam em torno dele, desde Teobaldo até Inezinha.

Encontramos ainda dois estudos de Nelson Werneck Sodré sobre o Naturalismo. O primeiro trata-se do capítulo intitulado "O episódio naturalista", da obra História da literatura brasileira. O mais interessante nesse texto é a introdução geral, em que compara as condições econômicas e europeias com a brasileira, no período em que escritores franceses e brasileiros produziram suas respectivas obras.

Para ele, Aluísio Azevedo foi um "ficcionista desigual, misto de grandezas e trivialidades" e que oscilava entre a crueza realista e a fantasia romântica. Apenas três livros são mencionados pelo estudioso: Casa de pensão ("em que há qualidades marcantes de ficcionista"), O Coruja ("rascunho de grande romance") e $O$ cortiço ("romance plenamente realizado") (SODRÉ, 1992, p. 391).

No mais, Werneck Sodré pouco diz por si mesmo sobre o movimento, pois apenas colige citações de Lúcia Miguel-Pereira, José Veríssimo e Olívio Montenegro e ressalta que entre nós o Naturalismo distanciou-se por demais da realidade e teve tendências regionalistas.

O outro estudo de Nelson Werneck que nos interessa para este artigo é o livro Naturalismo no Brasil. O título nos fez supor densa pesquisa sobre o movimento no

5 SILVA, M. Nogueira da. Prefácio. In: AZEVEDO, Aluísio. O Coruja. 6. ed. São Paulo: Livraria Martins Editora, 1954.
Brasil. Todavia, dos cinco capítulos da obra, apenas um é dedicado ao caso brasileiro e grande parte dele é sobre os grupos de intelectuais e escritores da Escola de Recife, da Academia Francesa e da Padaria Espiritual. Nas poucas páginas dedicadas à análise literária, reproduz-se o modelo do estudo anterior, pois trata das obras Casa de pensão, $O$ cortiço e $O$ homem, mas apenas citando e coligindo estudos de Lúcia Miguel-Pereira, Olívio Montenegro e Sílvio Romero.

Como vimos até aqui, Lúcia Miguel-Pereira é exaustivamente citada quando se fala do Naturalismo como um todo e da obra $O$ cortiço em particular. Sobre o romance $O$ Coruja, o texto de Alcides Maya é frequentemente mencionado, e apenas Eugênio Gomes e Nogueira da Silva avançam um pouco na leitura do romance. Quanto à influência francesa, ainda que seja comum a associação com Zola, muitos críticos apontam na obra do escritor maranhense uma filiação com Balzac e Eça de Queirós.

Para finalizar, apresentaremos estudiosos que, a nosso ver, fugiram de certa repetição presente em grande parte da crítica, ao apresentarem argumentos que permitem um outro olhar sobre a obra alusiana. São eles: Antonio Candido, Franklin de Oliveira e Massaud Moisés.

$\mathrm{Na}$ obra $O$ discurso e a cidade, Antonio Candido apresenta estudo lapidar sobre a obra alusiana no ensaio "De cortiço a cortiço". Não nos deteremos nele, pois não diz respeito especificamente ao romance por nós escolhido para estudo. Todavia, achamos por bem mencioná-lo, pois nesse ensaio o crítico apresenta não só uma análise da obra $O$ cortiço em uma perspectiva inédita - visto que apresenta essa obra em comparação com L'Assommoir, de Zola -, como também utiliza o que chama de "redução estrutural": "isto é, o processo por cujo intermédio a realidade do mundo e do ser se torna, na narrativa ficcional, componente de uma estrutura literária, permitindo que esta seja estudada em si mesma, como algo autônomo" (CANDIDO, 1973, p.9). Sobre esse ensaio, Arnoni Prado escreveu:

Antonio Candido na verdade é dos poucos, se não o único, a estudar as intenções naturalistas de Aluísio à luz da matriz europeia que o norteava, para transcrevê-la numa dimensão social que devassa a natureza econômica das relações de trabalho e contribui para fixar, num retrato tão autêntico quanto inovador, o significado profundo da coexistência social e humana entre exploradores e explorados na faina semiescravista do Brasil daquele tempo (PRADO, 2005, p. 52).

Já Franklin de Oliveira, apesar do tom ufanista do artigo dedicado a Aluísio Azevedo na década de 1970, inicia seu texto sobre o escritor exultando a tendência 
renovadora do grupo maranhense do século XIX, com destaque para Gonçalves Dias, Rocha Lima, Celso Magalhães e Nina Rodrigues, só para citar alguns da longa lista arrolada pelo crítico. Ele não só aponta alguns problemas nos estudos feitos até então sobre a obra alusiana, como alude aspectos sobre o romance $O$ Coruja que mereceram nossa atenção.

Segundo ele, diferentemente da geração de escritores franceses pós-1848, que "viram o homem menos como sujeito do que como objeto das circunstâncias sociais" (OLIVEIRA, 1978, p.74), Aluísio, ao implantar o Naturalismo no Brasil, conseguiu ultrapassar essa contradição. Daí o equívoco da crítica que, ao apontar para o excessivo romantismo em sua obra, não percebeu na verdade que o que havia ali era a busca da "autonomia do sujeito". Outro aspecto que ele rebate é a tendência geral de se elogiar a capacidade do escritor de movimentar cenas coletivas, mas não conseguir estudar o comportamento humano em sua individualidade. Ele refuta essa ideia da seguinte maneira:

Se com Aluísio o povo começa a ser o grande personagem do romance brasileiro, se a sua intenção crítica, quase pedagógica, refulge com vigor até em obras menores como A Condessa de Vésper (1902) [...], vemos que a sua pesquisa de tipos, fatos e situações, em diferentes camadas sociais, teria sido impossível se lhe faltasse capacidade de penetração psicológica - o seu poder de dar vida e corpo a agrupamentos humanos não elidia, antes, associava-se ao seu poder de desnudar a psicologia de cada agente das camadas sociais que representava. Esse poder é o poder de criar tipos (OLIVEIRA, 1978, p. 80).

Há outro aspecto importante levantado pelo estudioso que nos interessa. Ele considera que $O$ Coruja constitui ponto de transcendental importância na ficção brasileira, justamente porque Aluísio coloca como um dos temas centrais do romance o problema da bondade que gera desastres. Nesse sentido, André estaria na galeria de personagens universais, contra os quais se voltam as suas próprias virtudes, caso do príncipe Mischkin, da obra $O$ idiota (Dostoiévski) e Shen Te, de A alma boa de Setsuã (Brecht).

Passemos agora ao que disse Massaud Moisés sobre o romance $O$ Coruja. Depois das páginas preliminares, em que analisa o contexto histórico da produção literária no Brasil do último quartel do XIX, o crítico começa seu estudo de autores naturalistas e realistas por Aluísio Azevedo. Os primeiros romances citados são justamente os escritos como folhetim, que ele considera como "a faceta romântica" do escritor. Todavia, estranhamos o fato de $O$ Coruja não estar na lista de romances folhetinescos citados pelo crítico, que menciona apenas a publicação do romance, ocorrida em 1887, a despeito de apontar para as seguintes características do gênero, presentes na fatura da obra:

[...] $O$ Coruja: publicada em 1887 , não pertence ao grupo de obras escritas profissionalmente, e por isso tem merecido da crítica mais atenção. Ocorre, no entanto, que o prosador não teve como evitar a transposição de alguns vícios do folhetim para uma narrativa a que talvez desejasse emprestar a mesma gravidade com que elaborou $O$ Mulato e romances de igual têmpera (MOISES, 2001, p. 32).

Contudo, independentemente de Moisés ter desconsiderado o fato de o romance ter sido urdido inicialmente como folhetim, o crítico apresenta informação significativas sobre $O$ Coruja, pois é o único que aponta explicitamente para a possibilidade de a obra poder ser lida como um romance de formação: "O Coruja constitui uma 'educação sentimental', romance de aprendizagem, mas não da personagem que dá título à narrativa: o Coruja é figura secundária, ainda que relevante pelo papel desempenha. O 'Herói' é Teobaldo Henrique de Albuquerque" (MOISES, 2001, p. 32).

\begin{abstract}
Despido de intencionalidade científica ao pintar a burguesia decadente, sobretudo no flanco da política, O Coruja flutua entre o esteticismo com vistas ao entretenimento e o flagrante verídico da conjuntura finissecular. Nem mesmo o esboço da história do internato - prenunciando $O$ Ateneu -, que ocupa as primeiras páginas, salva a obra do limbo, de onde apenas a retira o leitor desejoso de conhecer mais essa faceta do autor e acompanhar uma narrativa à Macedo, vazada num estilo viril, plástico e de inflexão teatral pela predominância do diálogo (MOISES, 2001, p. 33).
\end{abstract}

Neste artigo, pretendemos mostrar que a recepção da obra $O$ Coruja pela crítica brasileira até o momento é escassa e bastante repetitiva. Esperamos que algumas questões apontadas por nós neste percurso possam suscitar o desejo de estudos mais aprofundados deste romance de Aluísio Azevedo.

\section{Referências}

AZEVEDO, Aluísio. Ficção completa. Rio de Janeiro: Aguilar, 2005. v. I e II.

CANDIDO, Antonio. O discurso e a cidade. São Paulo/Rio de Janeiro: Duas cidades/Ouro sobre Azul, 2004.

COUTINHO, Afrânio; COUTINHO, Eduardo de Faria. A literatura no Brasil: era realista, era de transição. São Paulo: Global, 1997.

GOMES, Eugênio. Aspectos do romance brasileiro. Salvador: Progresso, 1958. 
JÚNIOR, Araripe. A obra crítica de Araripe Júnior. v. 1. Rio de Janeiro: Casa de Rui Barbosa, 1958.

MAYA, Alcides. Discurso proferido na sessão solene extraordinária do dia 21 de julho de 1914 na Academia Brasileira de Letras. Disponível em: < http://www.academia. org.br/abl/media/Tomo\%20I\%20-\%201897\%20a\%201919. pdf>. Acesso em: jan. 2017.

MENEZES, Raimundo de. Prefácio. In: AZEVEDO, Aluísio. O Coruja. São Paulo: Martins, 1963.

MÉRIAN, Jean-Yves. Aluísio Azevedo: vida e obra (18571913). Rio de Janeiro: espaço e tempo, 1988.

MIGUEL-PEREIRA. Lúcia. História da literatura brasileira. Rio de Janeiro: José Olympio, 1957. v. XII.

MILLIET, Sérgio. Introdução ao romance O cortiço, de Aluísio Azevedo. São Paulo: Martins, 1959.

MOISES, Massaud. História da literatura brasileira: realismo e simbolismo. São Paulo: Cultrix, 2001.

MONTELLO, Josué. A ficção naturalista. In: COUTINHO, Afrânio; COUTINHO, Eduardo de Faria. A literatura no Brasil: era realista, era de transição (Org.). São Paulo: Global, 1997. p. 75 .
Aluísio Azevedo: trechos escolhidos. Rio de Janeiro: Agir, 1969.

OLIVEIRA, Franklin. Aluísio Azevedo. In: Literatura e civilização. Rio de Janeiro: Difel/MEC, 1978.

PRADO, Antonio Arnoni. Aluísio Azevedo e a crítica. In: AZEVEDO, Aluísio. Ficção completa em dois volumes. Rio de Janeiro: Nova Aguilar, 2005.

SILVA, M. Nogueira da. Prefácio. In: AZEVEDO, Aluísio. $O$ Coruja. 6. ed. São Paulo: Martins, 1954.

SODRÉ, Nélson Werneck. O naturalismo no Brasil. Belo Horizonte: Oficina de livros, 1992.

VERÍSSIMO, José. História da literatura brasileira: de Bento Teixeira (1601) a Machado de Assis (1908). Rio de Janeiro: Topbooks, 1998.

Autor:

MARIA ViAnA

Universidade Nova de Lisboa.

Lisboa, Portugal.

mariaviana8@uol.com.br

Recebido: $12 / 02 / 2017$

Aprovado: $15 / 08 / 2017$ 